\title{
Differential expression profiling of gene response to ionizing radiation in two endometrial cancer cell lines with distinct radiosensitivities
}

\author{
XUE-LIAN DU ${ }^{1,2}$, TAO JIANG ${ }^{2}$, ZE-QING WEN ${ }^{1}$, QING-SHUI LI ${ }^{2}$, RONG GAO $^{2}$ and FEI WANG ${ }^{1}$ \\ ${ }^{1}$ Department of Gynecologic Oncology, Shandong Tumor Hospital, Shandong University, Jinan 250117; \\ ${ }^{2}$ Department of Obstetrics and Gynecology, Provincial Hospital Affiliated to Shandong University, Jinan 250021, P.R. China
}

Received November 4, 2008; Accepted December 17, 2008

DOI: $10.3892 /$ or_00000265

\begin{abstract}
Although radiotherapy is routinely administered to high-risk endometrial carcinoma and offer a significant disease-free survival advantage, the therapeutic effect is sometimes limited by the occurrence of radioresistance. To determine the patterns of gene expression responsible for the radioresistance and to search for potential target genes for radiotherapy, we selected two cell lines with distinct radiosensitivities using colony-formation assay from four endometrial cancer cell lines. The cell cycle distribution showed higher fractions of $\mathrm{G}_{2} / \mathrm{M}$ phase cells in the radiosensitive cell line KLE after radiation compared with the radioresistant cell line ISK. Apoptosis assessment also showed significant elevation in the percentage of early apoptosis cells in KLE cells. Subsequently, gene expression changes after X-ray exposure were analyzed by using oligonucleotide microarrays. We identified, respectively, in ISK and KLE, 227 and 354 genes that exhibited $\geq 2$-fold difference. However, only 53 genes showing differences more than double the median expression value between the two groups were defined as radiosensitivity (or radioresistance)-related genes. Among these, genes associated with DNA-repair, apoptosis, growth factor, signal transduction, cell cycle and cell adhesion were predominant. The validity of the expression level of 10 randomly selected genes was confirmed by realtime PCR and/or Western blotting. In conclusion, the differential gene expression changes that occur after radiation in the two cell lines will provide insight into molecular mechanisms of radioresistance in endometrial carcinoma, and also the means to find potential targets to achieve further gains in therapeutic benefit.
\end{abstract}

Correspondence to: Dr Xue-Lian Du, Department of Gynecologic Oncology, Shandong Tumor Hospital, Shandong University, Jinan 250117, P.R. China

E-mail: duxuelian23800@yahoo.com.cn

Key words: endometrial cancer, radiosensitivity, microarray analysis

\section{Introduction}

Endometrial cancer is one of the most common gynecological malignancies worldwide. Surgery is the preferred initial treatment and most women with early-stage, low-risk disease will do well without adjuvant radiotherapy. However, both intermediate-risk and high-risk patients are at risk for localregional relapse and therefore adjuvant radiotherapy, such as pelvic radiation, vaginal brachytherapy, and whole-abdomen radiation, is essential for local control (1). Johnson and colleagues reported that adjuvant external-beam pelvic radiotherapy offered a significant disease-free survival advantage for high-risk endometrial cancer (2).

Although endometrial carcinoma was relatively radiosensitive as a group, great variance in the inherent radiation sensitivity between individual cell lines derived from endometrial carcinomas has been found (3). Moreover, the efficacy of this therapeutic modality is often limited by the occurrence of radioresistance, reflected as a diminished susceptibility of the irradiated cells to undergo apoptosis. Preliminary studies using microarray technology have generated a list of candidate biomarker genes that provide discrimination between radiosensitive and radioresistant cells in different types of malignant tumors (4-7), but none for endometrial cancer. This lack of data prompted us to carry out expression profiling on endometrial cancer cells with different radiosensitivity. The purpose of this study was to determine the patterns of gene expression responsible for radiosensitivity of endometrial cancer and search for potential target genes for radiotherapy.

\section{Materials and methods}

Cell lines and cultures. Human endometrial cancer cell lines ISK, RL95-2, HHUA and KLE were obtained from the Type Culture Collection of Chinese Academy of Sciences (Beijing, P.R. China). ISK (well differentiated) and KLE (poorly differentiated) were cultured in DMEM/F12 (GibcoBRL, Gaithersburg, MD). HHUA (well differentiated) and RL95-2 (moderately differentatied) were maintained in Dulbecco's modified Eagle's medium (Invitrogen, Carlsbad, CA) with $4.5 \mathrm{~g} / 1$ glucose. All media were supplemented with $10 \%$ fetal bovine serum, $2 \mathrm{mmol} / \mathrm{l}$ glutamine, and $100 \mathrm{U} / \mathrm{ml}$ 
Table I. Sequences of primers used for qRT-PCR.

\begin{tabular}{|c|c|c|c|}
\hline Gene symbol & Gene bank ID & Primer sequence & Annealing temperature $\left({ }^{\circ} \mathrm{C}\right)$ \\
\hline $\mathrm{ADM}$ & NM_001124 & $\begin{array}{l}\text { F: 5'-TTCAGCAGGGTATCGGAGC-3' } \\
\text { R: 5'-CCGACTGTTCAATGCTGCC-3' }\end{array}$ & 57 \\
\hline HMOX1 & NM_002133 & $\begin{array}{l}\text { F: 5'-CGCCTTCCTGCTCAACATT-3' } \\
\text { R: 5'-TGTGTTCCTCTGTCAGCATCAC-3' }\end{array}$ & 60 \\
\hline LOX & NM_002317 & $\begin{array}{l}\text { F: 5'-CTGCCTGGCCAGTTCAGCATAT-3' } \\
\text { R: 5'-TCCACTGGCAGTCTATGTCTGC-3' }\end{array}$ & 58 \\
\hline TNC & NM_002160 & $\begin{array}{l}\text { F: 5'-GTTTGGAGACCGCAGAGAAGAA-3' } \\
\text { R: 5'-TGTCCCCATATCTGCCCATCA-3' }\end{array}$ & 58 \\
\hline MMP-10 & NM_002425 & $\begin{array}{l}\text { F: 5'-CCTGATGTTGGTGGCTTCAGT-3' } \\
\text { R: 5'-CTGGTGTATAATTCACAATCCTGTAGGT-3' }\end{array}$ & 60 \\
\hline IL23A & NM_016584 & $\begin{array}{l}\text { F: 5'-GTGGGACATGGATCTAAGAGAAG-3' } \\
\text { R: 5'-TGGATCCTTTGCAAGCAGAAC-3' }\end{array}$ & 60 \\
\hline MDM2 & NM_006880 & $\begin{array}{l}\text { F: 5'-TGTAAGTGAACATTCAGGTG-3' } \\
\text { R: 5'-TTCCAATAGTCAGCTAAGGA-3' }\end{array}$ & 57 \\
\hline PRSS22 & NM_022119 & $\begin{array}{l}\text { F: 5'-CTATCATCGACTCGGAAGTC-3' } \\
\text { R: 5'-GATATGTGGGCAGGGTTACA-3' }\end{array}$ & 59 \\
\hline RGS2 & NM_002923 & $\begin{array}{l}\text { F: 5'-CGAGGAGAAGCGAGAAAAGA-3' } \\
\text { R: 5'-TTCCTCAGGAGAAGGCTTGA-3' }\end{array}$ & 60 \\
\hline HAS2 & NM_005328 & $\begin{array}{l}\text { F: 5'-TCGCAACACGTAACGCAAT-3' } \\
\text { R: 5'-ACTTCTCTTTTTCCACCCCATTT-3' }\end{array}$ & 77 \\
\hline GAPDH & NM_002046 & $\begin{array}{l}\text { F: 5'-GGGAGCCAAAAGGGTCATCATCTC-3' } \\
\text { R: 5'-CCATGCCAGTGAGCTTCCCGTTC-3' }\end{array}$ & 57 \\
\hline
\end{tabular}

$\mathrm{F}$, forward primer; $\mathrm{R}$, reverse primer.

penicillin/streptomycin. The cultures were incubated at $37^{\circ} \mathrm{C}$ in a humidified $5 \% \mathrm{CO}_{2}$ incubator.

Clonogenic cell survival assay. Survival following radiation exposure was defined as the ability of the cells to maintain clonogenic capacity and form colonies. Cells were cultured until 70-80\% confluent, and then exposed to X-rays from a VARIAN clinical 2100C/D linear accelerator (Palo Alto, CA) at a dose rate of $2.0 \mathrm{~Gy} / \mathrm{min}$. Subsequently, cells were trypsinized and transferred to 6 -well plates at $1 \times 10^{3}$ cells/ well in complete culture medium. After 10 days of incubation, colonies were fixed and stained in $2 \%$ crystal violet in absolute ethanol. Colonies consisting of $\geq 50$ cells were scored, and five replicate dishes were counted for each treatment. The plating efficiency was calculated for each well by dividing the number of colonies by the original number of cells plated. The surviving fraction was normalized to control cell plating efficiency by dividing the plating efficiency of treated cells by that of control cells.

Cell cycle analysis. After exposure to 6 Gy radiation, cells were harvested by trypsinization (Invitrogen), washed with PBS, fixed, and stored at $4^{\circ} \mathrm{C}$ before DNA analysis. After removal of ethanol, cells were washed again in PBS and stained for $30 \mathrm{~min}$ at room temperature with $1 \mathrm{ml}$ DNA fluorochrome solution containing $200 \mu \mathrm{g}$ propidium iodide (Sigma, St. Louis, MO), 0.1\% Triton X-100 (Sigma), and 2 mg DNase-free ribonuclease A (Sigma). Resulting DNA distri- butions were analyzed using a FACScan flow cytometer (Becton-Dickinson Co., San Jose, CA) for the proportion of cells in $\mathrm{G}_{0} / \mathrm{G}_{1}, \mathrm{~S}$ and $\mathrm{G}_{2} / \mathrm{M}$ phases of the cell cycle.

Assessment of apoptosis. The Annexin V-FITC kit (BD Biosciences, San Diego, CA) was used to detect early apoptotic activity of cells exposed to 6 Gy radiation according to the manufacturer's instructions, with slight modifications. The apoptotic percentage of 10,000 cells was determined, after which all the experiments reported in this study were performed 3 times. The data were analyzed using WinMDI 2.8 software (Scripps Institute, La Jolla, CA) for calculation of percentage cells with apoptosis per group.

RNA extraction and microarray analysis. Total RNA was harvested from cells before and $1 \mathrm{~h}$ after 6 Gy radiation exposure using TRIzol (Invitrogen), concentrated using isopropyl alcohol precipitation, and further purified using RNeasy Mini kit (Qiagen, Valencia, CA) according to the manufacturer's protocols. The quantity and quality of the purified RNA were assessed by OD260 and OD280 measurements on a spectrophotometer and the integrity was determined by formaldehyde denatured gel electrophoresis.

Microarray experiments were performed using a $22 \mathrm{~K}$ Human Genome Oligonucleotide Microarray Kit containing 21,329 well-characterized Homo sapiens genes (CapitalBio Corp., Beijing, P.R. China) following the manufacturer's instructions. The cDNA probes were synthesized by reverse 
Table II. Genes that were expressed at least 3-fold higher in ISK/ISK-R.

\begin{tabular}{|c|c|c|c|c|}
\hline GeneBank ID & Name & Description & Fold & Function \\
\hline NM_001124 & ADM & Adrenomedullin & 6.984 & Cell-cell signaling signal \\
\hline NM_002133 & HMOX1 & Heme oxygenase 1 & 5.978 & Transducer activity \\
\hline NM_015675 & GADD45B & $\begin{array}{l}\text { Growth arrest and DNA-damage- } \\
\text { inducible, } \beta\end{array}$ & 5.698 & $\begin{array}{l}\text { Cell cycle, apoptosis, MAPK signaling } \\
\text { pathway }\end{array}$ \\
\hline NM_003806 & HRK & Harakiri, BCL2 interacting protein & 5.342 & Regulation of apoptosis \\
\hline NM_002317 & LOX & Lysyl oxidase & 4.921 & Extracellular matrix \\
\hline NM_002193 & INHBB & Inhibin, $B$ B & 4.581 & Growth factor activity \\
\hline NM_001878 & CRABP2 & Cellular retinoic acid binding protein 2 & 4.234 & Histogenesis, lipid binding \\
\hline NM_002160 & $\mathrm{HXB}$ & Hexabrachion & 3.651 & Extracellular matrix, focal adhesion \\
\hline NM_005655 & TIEG & TGFB inducible early growth response & 3.639 & Cell-cell signaling, cell proliferation \\
\hline NM_002425 & MMP10 & Matrix metalloproteinase 10 & 3.470 & Breakdown of extracellular matrix \\
\hline NM_003364 & UPP1 & Uridine phosphorylase & 3.450 & Pyrimidine metabolism \\
\hline NM_014371 & NAKAP95 & Neighbor of A-kinase anchoring protein 95 & 3.447 & Enzyme binding \\
\hline NM_024017 & HOXB9 & Homeo box B9 & 3.085 & $\begin{array}{l}\text { Cell cycle, RB suppressor/checkpoint } \\
\text { signaling in response to DNA damage }\end{array}$ \\
\hline NM_006159 & NELL2 & NEL-like 2 (chicken) & 3.027 & Growth regulation, differentiation \\
\hline NM_005347 & HSPA5 & Heat shock $70 \mathrm{kDa}$ protein 5 & 3.011 & MAPK signaling pathway \\
\hline
\end{tabular}

transcription and purified as previously described (8). Cy5 and Cy3-dCTP-labeled DNA were hybridized to the microarray according to the manufacturer's recommendations. Arrays were scanned with LuxScan 10K/A double channel laser scanner (CapitalBio Corp.). For each test and control sample, two hybridizations were performed by using a reverse fluorescence strategy. Differential expression was determined using the combined basis of t-test with $\mathrm{P}<0.05$ and fold changes (either up or down) of $\geq 2$-fold. Only genes whose alteration tendency was consistent (both above 2-fold) in both microarrays were selected as differentially expressed genes. All differentially expressed genes were analyzed using Molecular Annotation System 5.0 (MAS 5.0, www. capitalbio.com) which integrates three pathway resourcesKEGG, BioCarta and GenMAPP.

Quantitative real-time polymerase chain reaction $(P C R)$ validation. Real-time PCR was performed on an ABI Prism 7000 Sequence Detection System using SYBR-Green RTPCR Kit (Applied Biosystems, Foster City, CA, USA) according to the manufacturer's protocols. The primers used for real-time PCR are shown in Table I. The protocol of real-time PCR was as follows: initiation with a 10-min denaturation at $95^{\circ} \mathrm{C}$, followed by 40 cycles of amplification at $95^{\circ} \mathrm{C}(10 \mathrm{sec})$ for denaturation, $55^{\circ} \mathrm{C}(10 \mathrm{sec})$ for annealing, and $72^{\circ} \mathrm{C}$ for extension. The real-time PCR amplification product was analyzed by melting curve analysis and $1.2 \%$ agarose gel electrophoresis, respectively. Fold change was determined based on average cycle threshold $(\mathrm{Ct})$ values for triplicates. Gene expression levels were calculated and presented with $2^{-\Delta \Delta \mathrm{Ct}}$ values.

Analysis of protein expression by Western blot. Seventyfive percent confluent cells were irradiated with 6 Gy $\mathrm{X}$-rays. After $1 \mathrm{~h}$, cells were harvested and lysed with cold
RIPA buffer. Total cell lysates were clarified by centrifugation $(14,000 \mathrm{rpm}, 20 \mathrm{~min})$ at $4^{\circ} \mathrm{C}$. Protein concentrations were measured with the MicroBCA kit (Pierce Inc. Rockford, IL). Then $20 \mu \mathrm{g}$ of each soluble protein sample was separated by $10 \%$ SDS-polyacrylamide gel electrophoresis (PAGE) and transferred to a nitrocellulose membrane. After blocking with 5\% TBST-milk, membranes were incubated with mouse monoclonal anti-ADM (1:2 500), anti-LOX, antiMMP10, rabbit polyclonal anti-IL23A (Santa Cruz Biotechnology, Santa Cruz, CA), anti-MYC and anti- HAS2 (Stressgen Biotechnologies) and anti- $\beta$-actin (Sigma) antibodies overnight at $4^{\circ} \mathrm{C}$. Then the membranes were incubated with horseradish peroxidase (HP)-conjugated anti-rabbit or anti-mouse IgG antibody, respectively (Santa Cruz Biotechnology). Membranes were incubated in SuperSignal ${ }^{\circledR}$ West Pico Chemiluminescent Substrate (Pierce), exposed to CL-Xposure Film ${ }^{\mathrm{TM}}$ (Pierce) and developed using an All-Pro 100 Plus automated X-ray film processor (All-Pro Imaging Corporation, Hicksville, NY). The resultant bands were quantified using AlphaEaseFC ${ }^{\mathrm{TM}}$ software (AlphaInnotech, San Leandro, CA).

Statistical analysis. Data were analyzed with SPSS 10.0 statistical software (SPSS, Chicago, IL, USA). Comparisons of survival fractions in the clonogenic assays among the various treatment groups were analyzed by two-tailed unpaired Student's t-test. Comparisons between means in the Western blot were analyzed by Student's t-test. A p-value $<0.05$ was considered statistically significant.

\section{Results}

Clonogenic cell survival assay. Cells from the ISK, HHUA, RL95-2, and KLE cell lines were irradiated, and survival curves were determined from the postirradiated cells by 


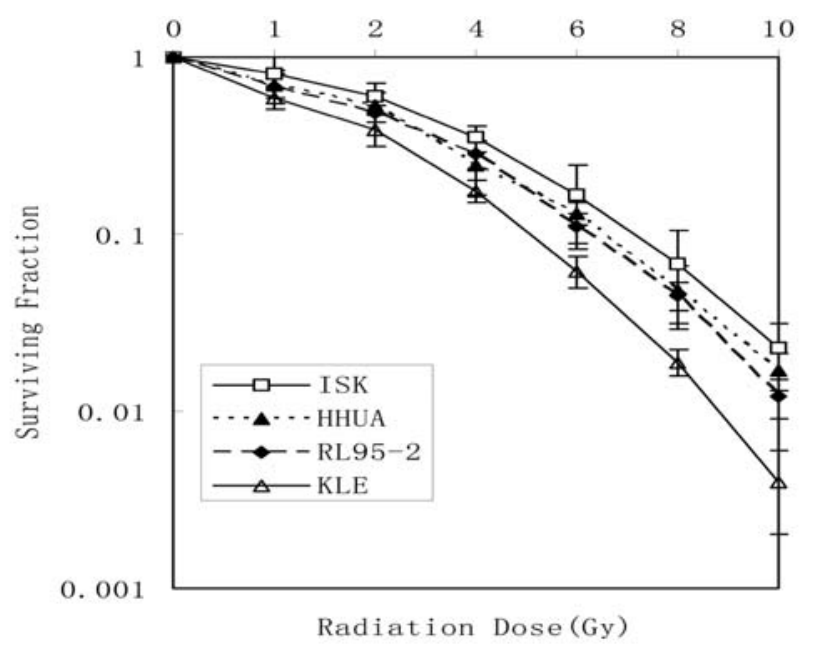

Figure 1. Clonogenic survival curves for ISK, HHUA, RL95-2 and KLE cells exposed by X-ray radiation. Cells were seeded onto 6-well plate and further irradiated with various doses $(0-10 \mathrm{~Gy})$. Then the cells were cultured for 10 days, and the number of surviving colonies (defined as a colony with 50 cells) was counted. Error bars, SDs of results in five independent experiments.

colony formation assay. Fig. 1 depicts clonogenic survival curves for the four cell lines exposed by X-ray radiation. Cell line KLE was classified as radiation-sensitive, and cell lines ISK were classified as relatively radiation resistant.

Cell cycle arrest after irradiation. The capacity of radiation to inhibit cell cycle progression was evaluated via flow cytometry. As shown in Fig. 2, radiation caused a significant
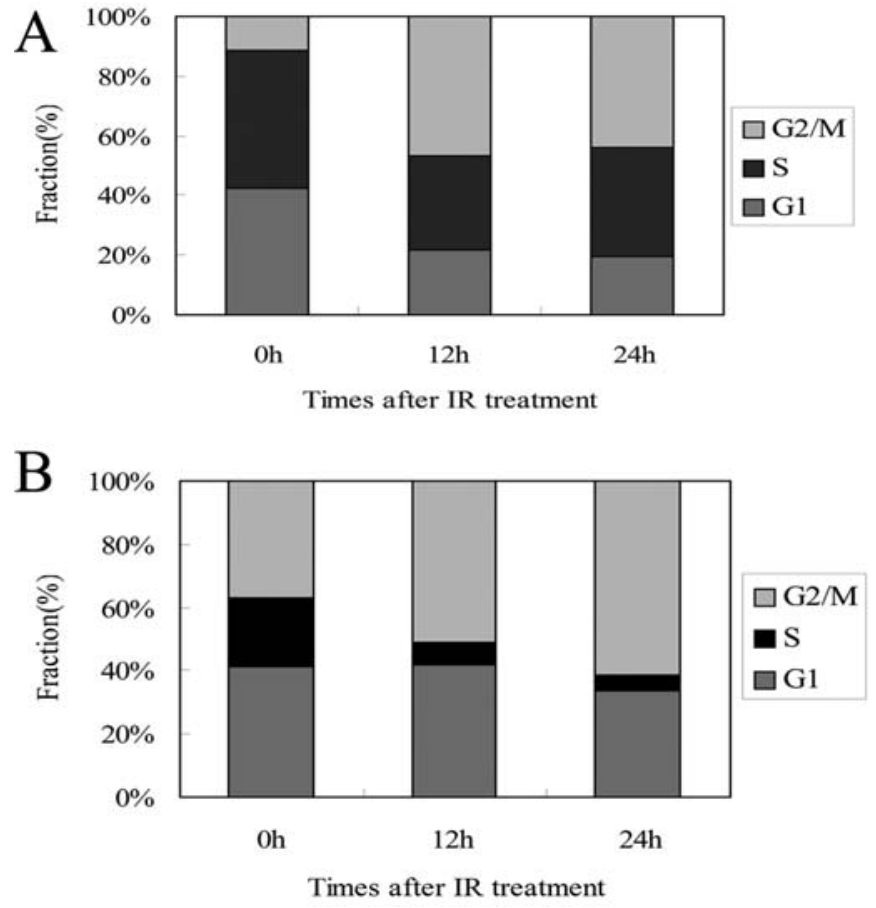

Figure 2. Representative flow cytometric analysis of cell cycle phase distribution. ISK (A) and KLE (B) cells were harvested 12 or $24 \mathrm{~h}$ after exposure to radiation (6 Gy). Cell cycle distribution was subsequently determined by flow cytometry.

decrease in S-phase cell population (46.5\% vs. $36.7 \%$ in ISK and $21.9 \%$ vs. $6.9 \%$ in KLE cells, respectively), accompanied by a concomitant accumulation in the $\mathrm{G}_{2} / \mathrm{M}$-phase cell
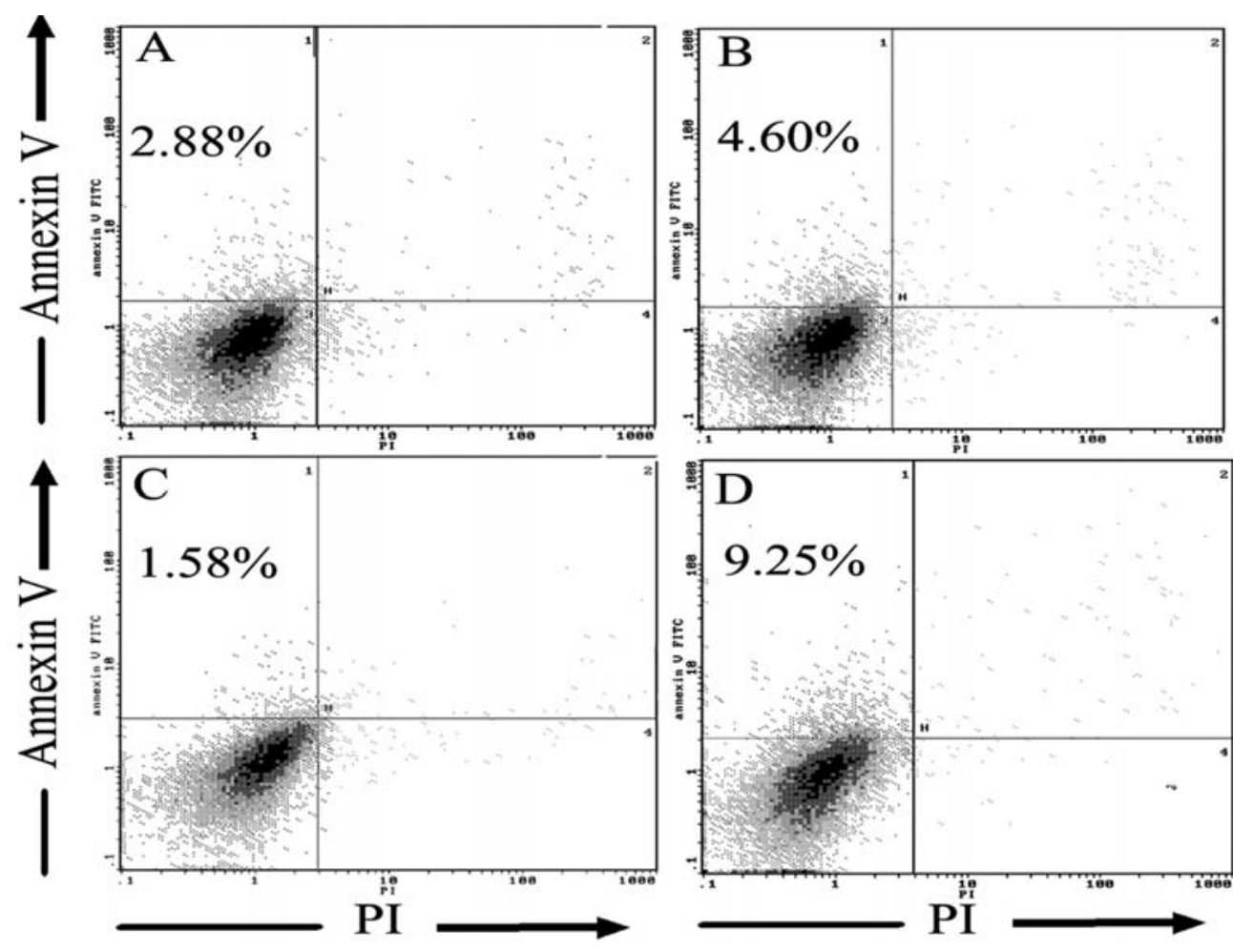

Figure 3. Representative flow cytometric analysis of IR-induced apoptosis. The dot plot diagrams represent typical apoptotic cell populations detected by Annexin V-FITC and PI staining. (A) Untreated ISK cells. (B) ISK cells treated by radiation (6 Gy). (C) Untreated KLE cells. (D) KLE cells treated by radiation (6 Gy). The upper left quadrants represent apoptotic cells, which, were positive for Annexin V-FITC and negative for PI (FITC+/PI-). 


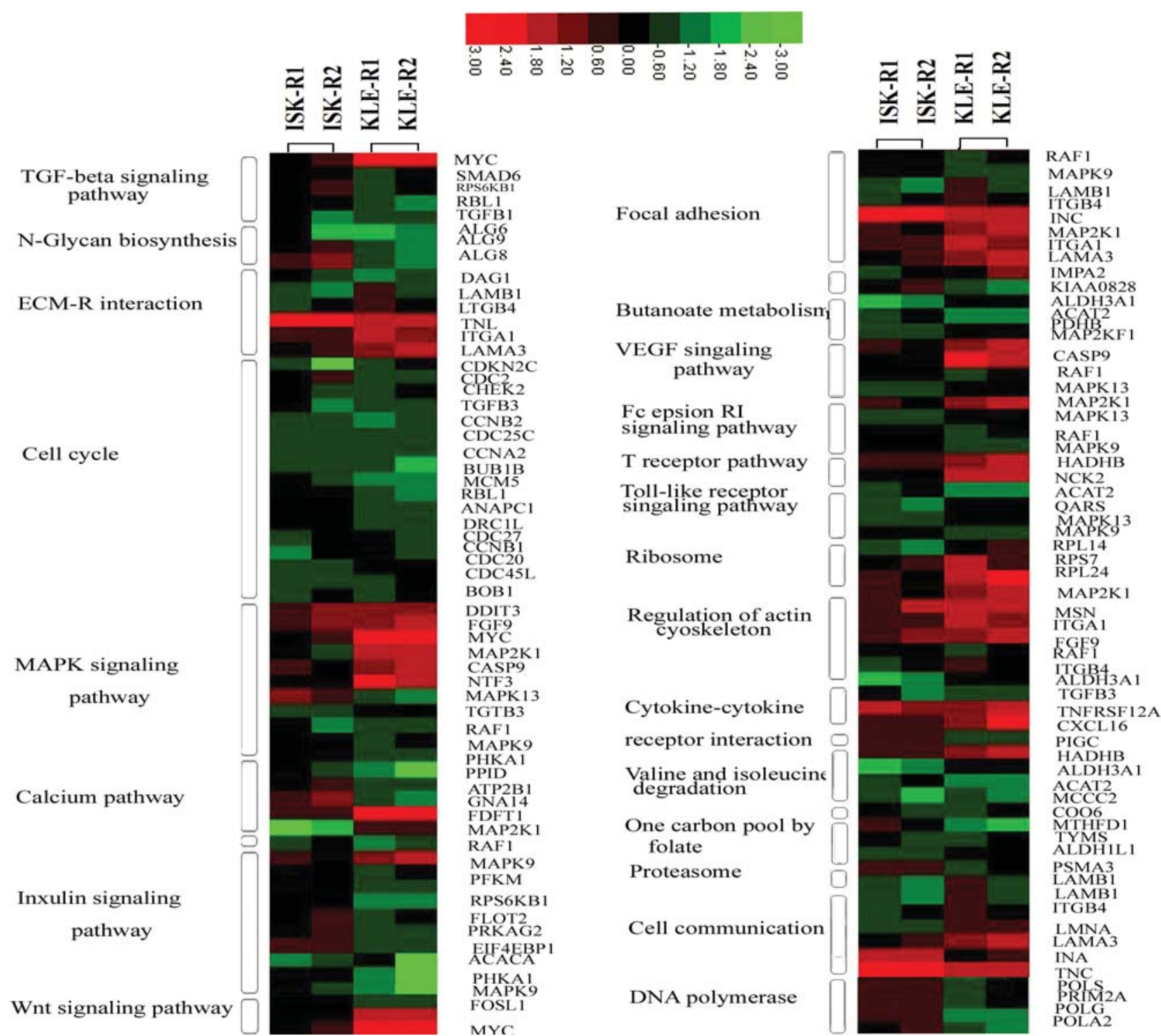

Figure 4. Pathway analysis of selected genes differentially regulated by radiation in ISK and KLE cells. Color intensity is assigned to ratios of gene expression; shades of red, genes that are up-regulated; shades of green, genes that are down-regulated; black, genes that are unchanged.

population $(11.3 \%$ vs. $43.9 \%$ in ISK and $37 \%$ vs. $61.4 \%$ in KLE), $24 \mathrm{~h}$ after ionizing radiation (IR) treatment. The cell cycle distribution showed higher fractions of $\mathrm{G}_{2} / \mathrm{M}$ phase cells in KLE cells before, 12 and $24 \mathrm{~h}$ after radiation treatment compared with ISK $(\mathrm{P}<0.05)$. However, although test results were reproducible and consistent, the difference of decreased S-phase fraction between two cell lines did not yield statistical significance $(\mathrm{P}>0.05)$.

Effects on apoptosis rate. To investigate the effects of irradiation on the induction of apoptosis in ISK and KLE cells, Annexin V-FITC/PI staining and flow cytometric measurement were used to quantify the percentages of apoptosis in the total cell population. As shown in Fig. 3, after irradiation for $24 \mathrm{~h}$, the percentages of early apoptosis cells (Annexin V+/PI-) increased from 1.58 to $9.25 \%$ in KLE cells and 2.88 to $4.60 \%$ in ISK cells, respectively. Significant elevation in the percentage of apoptosis cells were observed in KLE cells than ISK cells $(\mathrm{P}<0.05)$. These results suggest that radiation is more effective in inducing early apoptosis in KLE cells than in ISK cells.

Gene expression profiling of ISK and KLE cells in response to $X$-ray radiation. Microarray analysis revealed distinct gene expression patterns of temporal gene response to X-ray radiation in the two cell lines. There were 227 (70 upregulated and 157 down-regulated) and 354 (121 upregulated and 233 down-regulated) differentially expressed genes in ISK and KLE cells, respectively. Tables II and III show genes that were expressed at least 3-fold higher in ISK/ISK-R and KLE/KLE-R, respectively) We also categorized the differently expressed genes by pathway analysis. The temporal expression genes were associated with cell cycle, DNA damage and repair, MAPK signaling pathway, cell adhesion, metabolism and so on. The $\log _{2}$ transformed data of the genes regulated by IR in ISK and KLE cells are shown as hierarchical cluster diagrams (Fig. 4). 
Table III. Genes that were expressed at least 3-fold higher in KLE/KLE-R.

\begin{tabular}{|c|c|c|c|c|}
\hline GeneBank ID & Name & Description & Fold & Function \\
\hline NM_016584 & IL23A & Interleukin $23, \alpha$ subunit p19 & 22.919 & Cytokine-cytokine receptor interaction \\
\hline NM_002575 & SERPINB2 & $\begin{array}{l}\text { Serine proteinase inhibitor, clade B, } \\
\text { member } 2\end{array}$ & 11.997 & $\begin{array}{l}\text { Protease inhibitor activity, regulation } \\
\text { of apoptosis }\end{array}$ \\
\hline NM_080489 & SDCBP2 & Syndecan binding protein 2 & 8.433 & Neurogenesis \\
\hline NM_022119 & PRSS22 & Protease, serine, 22 & 7.447 & Chymotrypsin activity \\
\hline NM_002923 & RGS2 & Regulator of G-protein signaling 2, $24 \mathrm{kDa}$ & 6.868 & Multifunctional signaling centers \\
\hline NM_005114 & HS3ST1 & Heparan sulfate 3-O-sulfotransferase 1 & 5.862 & Heparan sulfate biosynthesis \\
\hline NM_005328 & HAS2 & Hyaluronan synthase 2 & 5.355 & Transferase activity \\
\hline NM_014330 & PPP1R15A & $\begin{array}{l}\text { Protein phosphatase } 1 \text {, } \\
\text { regulatory subunit } 15 \mathrm{~A}\end{array}$ & 5.284 & $\begin{array}{l}\text { Response to DNA damage stimulus, } \\
\text { apoptosis }\end{array}$ \\
\hline NM_012385 & P8 & $\mathrm{P} 8$ protein & 5.070 & Apoptosis, cell size regulation \\
\hline NM_032489 & ACRBP & Acrosin binding protein & 4.751 & Apoptosis, coenzyme metabolism \\
\hline NM_005737 & ARL7 & ADP-ribosylation factor-like 7 & 4.654 & GTPase activity \\
\hline NM_007052 & NOX1 & NADPH oxidase 1 & 4.605 & Apoptosis \\
\hline NM_005252 & FOS & $\begin{array}{l}\text { V-fos FBJ murine osteosarcoma } \\
\text { viral oncogene homolog }\end{array}$ & 4.574 & $\begin{array}{l}\text { MAPK signaling pathway, TGF } \beta \\
\text { signaling pathway, inhibition of } \\
\text { cellular proliferation }\end{array}$ \\
\hline NM_002467 & MYC & $\begin{array}{l}\text { V-myc myelocytomatosis } \\
\text { viral oncogene homolog }\end{array}$ & 4.241 & $\begin{array}{l}\text { Cell cycle progression, apoptosis and } \\
\text { cellular transformation }\end{array}$ \\
\hline NM_032549 & IMMP2L & $\begin{array}{l}\text { Inner mitochondrial membrane } \\
\text { peptidase } 2 \text { like }\end{array}$ & 4.073 & Microsome, vesicular fraction \\
\hline NM_001964 & EGR1 & Early growth response 1 & 3.662 & MAP kinase pathway regulation \\
\hline NM_003633 & ENC1 & Ectodermal-neural cortex & 3.570 & Cytoskeleton, neurogenesis \\
\hline NM_005319 & $\mathrm{H} 1 \mathrm{~F} 2$ & H1 histone family member 2 & 3.445 & Chromatin assembly \\
\hline NM_001229 & CASP9 & Caspase- 9 & 3.126 & Apoptosis \\
\hline NM_004073 & CNK & Cytokine-inducible kinase & 3.013 & Regulation of cell cycle \\
\hline
\end{tabular}

Comparison of gene expression profiles of ISK and KLE in response to radiation. When the gene expression profiles of ISK and KLE cells in response to radiation were compared, it was found that 66 genes were commonly regulated in a similar manner in both groups (data not shown). In ISK 161 genes and in KLE cells 288 genes were exclusively regulated by radiation. However, because more than half of these genes have small differences in expression level between groups, the difference might be caused by data fluctuation. Therefore, genes showing differences more than double the median expression value between the two groups $\left(\mu \mathrm{X}_{\mathrm{ISK}} / \mu \mathrm{X}_{\mathrm{KLE}} \leq 0.5\right.$ or $\geq 2.0$, where $\mu \mathrm{X}_{\mathrm{ISK}}$ and $\mu \mathrm{X}_{\mathrm{KLE}}$ indicate median $X$ values for the ISK or KLE group, respectively; and $\mathrm{X}=$ the $\mathrm{Cy} 5 / \mathrm{Cy} 3$ signal intensity ratio for each gene and for each sample) were defined as radiosensitivity (or radioresistance)-related genes. We selected a total of 53 genes as being differently expressed between ISK and KLE groups. Of those 53 genes, 24 revealed increased expression, and 29 showed decreased expression, in ISK group compared with KLE group (Table IV). To investigate the biological functions involved in the discriminating genes, we performed Gene Ontology category analysis. According to the gene function, categories of apoptosis, growth factor, and cell adhesion molecule activity, showed significantly higher proportion among selected 53 genes.
The list of genes up-regulated in ISK cells included a member of growth factor (NELL2, INHBB), proliferation regulator (HOXB9 GADD45B), as well as genes related to cell communication (TYRO3) or extracellular matrix (LOX). Genes that are considered to be associated with repair of breaks in double-stranded DNA, including DNA repair protein RAD51 homolog 3 (RAD51C) and Rad3 related protein (ATR) were also elevated in the ISK group. Genes up-regulated in KLE cells include mitogen-activated protein kinase kinase 1 (MAP2K1), regulator of G-protein signaling 2 (RGS2), and RAB2 (a member of the RAS oncogene family). In addition, among six genes related to apoptosis, P8 protein (P8) and programmed cell death 5 (PDCD5), which induce apoptosis, showed significantly higher expression in KLE cells. On the other hand, four genes, Cysteine-rich 61 (CYR61), Apolipoprotein E (APOE), Mdm2 p53 binding protein homolog (MDM2) and Heat shock $70 \mathrm{kDa}$ protein 5 (HSPA5), which inhibit apoptosis, showed higher expression in ISK cells.

Validation of microarray results by quantitative RT-PCR. To show the reproducibility of the microarray analysis, 10 genes were selected at random, spanning a range of foldchanges (3.4-22.9; Fig. 5). The microarray analysis identified ADM (6.9-fold), HMOX1 (6.0-fold), LOX (4.9-fold), TNC (3.7-fold), and MMP10 (3.5-fold) as being significantly 
Table IV. Candidate genes that were detected by oligonucleotide microarray analysis between ISK and KLE cells after radiation treatment.

\begin{tabular}{|c|c|c|c|}
\hline GeneBank ID & Name & Description & Ratio ISK/KLE) \\
\hline \multicolumn{4}{|l|}{ Increase } \\
\hline NM_001184 & ATR & Ataxia telangiectasia and $\operatorname{Rad} 3$ related & 6.944 \\
\hline NM_015675 & GADD45B & Growth arrest and DNA-damage-inducible, $\beta$ & 5.705 \\
\hline NM_003806 & HRK & Harakiri, BCL2 interacting protein & 5.546 \\
\hline NM_002133 & HMOX1 & Heme oxygenase 1 & 5.374 \\
\hline NM_002317 & LOX & Lysyl oxidase & 5.097 \\
\hline NM_006159 & NELL2 & NEL-like 2 & 4.821 \\
\hline NM_002193 & INHBB & Inhibin, $\beta \mathrm{B}$ & 4.812 \\
\hline NM_005347 & HSPA5 & Heat shock $70 \mathrm{kDa}$ protein 5 & 4.292 \\
\hline NM_002876 & RAD51C & RAD51 homolog C (S. cerevisiae) & 3.723 \\
\hline NM_002160 & $\mathrm{HXB}$ & Hexabrachion & 3.599 \\
\hline NM_080927 & ESDN & Discoidin, CUB and LCCL domain containing 2 & 3.263 \\
\hline NM_006080 & SEMA3A & $\begin{array}{l}\text { Sema domain, immunoglobulin domain (Ig), } \\
\text { short basic domain, secreted (semaphorin) } 3 \mathrm{~A}\end{array}$ & 3.257 \\
\hline NM_032727 & INA & Internexin neuronal intermediate filament protein, $\alpha$ & 3.192 \\
\hline NM_002425 & MMP10 & Matrix metalloproteinase 10 (stromelysin 2) & 3.143 \\
\hline NM_005655 & TIEG & TGFB inducible early growth response & 3.096 \\
\hline NM_021627 & SENP2 & SUMO1/sentrin/SMT3 specific peptidase 2 & 3.047 \\
\hline NM_006880 & MDM2 & Mdm2, transformed $3 \mathrm{~T} 3$ cell double minute $2, \mathrm{p} 53$ binding protein & 2.530 \\
\hline NM_024017 & HOXB9 & Homeobox B9 & 2.351 \\
\hline NM_002899 & RBP1 & Retinol binding protein 1 , cellular & 2.324 \\
\hline NM_014371 & NAKAP95 & Neighbor of A-kinase anchoring protein 95 & 2.286 \\
\hline NM_204627 & TYRO3 & TYRO3 protein tyrosine kinase & 2.203 \\
\hline NM_005345 & HSP70-1A & Heat shock $70 \mathrm{kDa}$ protein $1 \mathrm{~A}$ & 2.184 \\
\hline NM_000041 & APOE & Apolipoprotein E & 2.113 \\
\hline NM_015714 & G0S2 & G0/G1switch 2 & 2.059 \\
\hline \multicolumn{4}{|l|}{ Decrease } \\
\hline NM_001554 & CYR61 & Cysteine-rich, angiogenic inducer, 61 & 0.499 \\
\hline NM_004542 & B9 & NADH dehydrogenase $1 \alpha$ subcomplex 3 & 0.487 \\
\hline NM_014038 & HSPC028 & Basic leucine zipper and W2 domains 2 & 0.482 \\
\hline NM_001034996 & RPL14 & Ribosomal protein L14 & 0.479 \\
\hline NM_012190 & FTHFD & Aldehyde dehydrogenase 1 family, member L1 & 0.477 \\
\hline NM_031966 & CCNB1 & Cyclin B1 & 0.470 \\
\hline NM_002865 & RAB2A & RAB2A, member RAS oncogene family & 0.463 \\
\hline NM_014214 & IMPA2 & Inositol(myo)-1(or 4)-monophosphatase 2 & 0.462 \\
\hline NM_001005619 & ITGB4 & Integrin, $B 4$ & 0.453 \\
\hline NM_007254 & PNKP & Polynucleotide kinase 3'-phosphatase & 0.434 \\
\hline NM_170708 & LMNA & Lamin $\mathrm{A} / \mathrm{C}$ & 0.420 \\
\hline NM_014234 & FABGL & Hydroxysteroid (17-ß) dehydrogenase 8 & 0.408 \\
\hline NM_006339 & HMG20B & High-mobility group 20B & 0.404 \\
\hline NM_080734 & WFDC2 & WAP four-disulfide core domain 2 & 0.400 \\
\hline NM_000048 & ASL & Argininosuccinate lyase & 0.376 \\
\hline NM_000368 & TSC & Tuberous sclerosis 1 & 0.375 \\
\hline NM_002755 & MAP2K1 & Mitogen-activated protein kinase kinase 1 & 0.372 \\
\hline NM_001513 & GSTZ1 & Glutathione transferase zeta 1 & 0.366 \\
\hline NM_002528 & NTHL1 & nth endonuclease III-like 1 & 0.354 \\
\hline NM_002291 & LAMB1 & Laminin, $B 1$ & 0.348 \\
\hline NM_012385 & P8 & $\mathrm{P} 8$ protein (candidate of metastasis 1 ) & 0.331 \\
\hline NM_001914 & CYB5A & Cytochrome b5 type A (microsomal) & 0.318 \\
\hline NM_012449 & STEAP & Six transmembrane epithelial antigen of the prostate 1 & 0.305 \\
\hline NM_002923 & RGS2 & Regulator of G-protein signalling 2, $24 \mathrm{kDa}$ & 0.281 \\
\hline NM_004058 & CAPS & Calcyphosine & 0.185 \\
\hline NM_002864 & PZP & Pregnancy-zone protein & 0.170 \\
\hline NM_001747 & CAPG & Capping protein (actin filament), gelsolin-like & 0.146 \\
\hline NM_004297 & GNA14 & Guanine nucleotide binding protein, $\alpha 14$ & 0.098 \\
\hline NM_015685 & SDCBP2 & Syndecan binding protein (syntenin) 2 & 0.040 \\
\hline
\end{tabular}




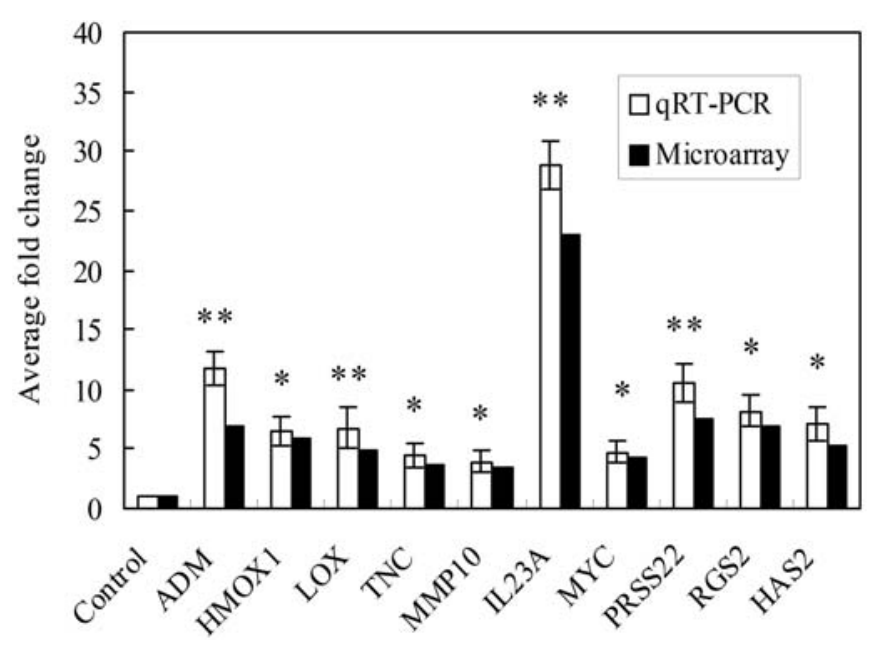

Figure 5. Quantitative real-time PCR validation of microarray data. Microarray validation of 10 genes differentially regulated by radiation (6 Gy) in ISK (ADM, HMOX1, LOX, TNC and MMP10) and KLE (IL23A, MYC, PRSS22, RGS2 and HAS2) were performed using quantitative RT-PCR. RT-PCR was done in triplicate and the ratio was calculated relative to the housekeeping genes GAPDH. Error bars, SD of results in three independent experiments. ${ }^{*} \mathrm{P}<0.05$ versus control; ${ }^{* *} \mathrm{P}<0.01$ versus control.

increased in ISK group, IL23A (22.9-fold), MYC (4.2-fold), PRSS22 (7.4-fold), GS2 (6.8-fold), and HAS2 (5.4-fold) in KLE group, and these changes were validated by real-time RT-PCR. Fig. 5 shows relative gene expression compared with control cells. These data provide important confirmation of the gene expression alterations identified by the microarray analysis.

Western blot analysis. To examine whether the gene expression alterations identified by the microarray analysis and qRT-PCR also occur at the protein level, we performed
Western blot analysis for 6 proteins. Increased expression of ADM, LOX, and MMP10 protein in radiation treated ISK cells and elevated expression of IL23A, MYC, and HAS2 in radiation treated KLE were confirmed at the protein level (Fig. 6).

\section{Discussion}

Microarray analysis is a powerful tool for obtaining comprehensive information on expression of thousands of genes in cancer cells. There have been a few studies aimed at predicting response to radiotherapy using gene expression profiling in the treatment of esophageal, rectal, nasopharyngeal cancer and neuroblastoma $(4,6,10,11)$. Identification of the genes differentially expressed between radiosensitive and radioresistant cancers may provide new insights into the mechanisms underlying clinical radioresistance and improve the efficacy of radiotherapy (11). Although the role of radiotherapy is essential in the treatment of endometrial carcinoma, present knowledge of the radiation sensitivity of this kind of malignacy is mostly empirical and based on clinical trials. To elucidate the further molecular events involved in radiosensitivity of endometrial cancer, we examined global expression patterns of two cell lines with different radiosensitivities.

In the present study, we found genes that showed different expression patterns between two cell lines of distinct radiosensitivities and, therefore, were likely to reflect differences in the response of endometrial cancer cells to radiotherapy. Many genes associated with DNA-repair, apoptosis, growth factor, signal transduction, cell cycle and cell adhesion were obviously differently expressed between the two cell lines, and similar results had been reported in certain types of malignant cells by previous studies $(12,13)$. This list of genes may be useful when attempting to predict and sensitize the radioresistant endometrial cancer cells.
ISK ISK ISK-R ISK-R
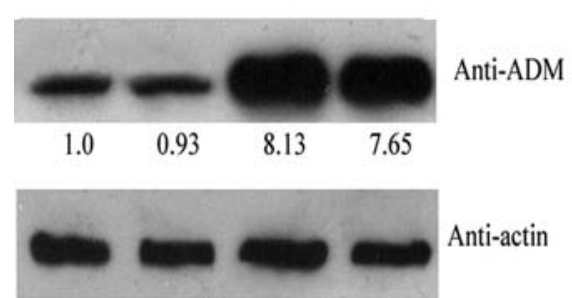

KLE KLE KLE-R KLE-R

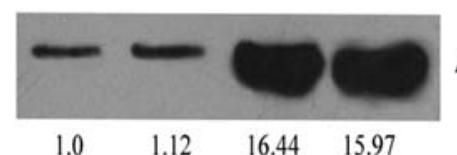

Anti-IL23A

$\begin{array}{llll}1.0 & 1.12 & 16.44 & 15.97\end{array}$

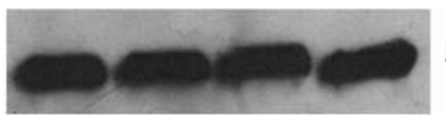

Anti-actin
ISK ISK ISK-R ISK-R
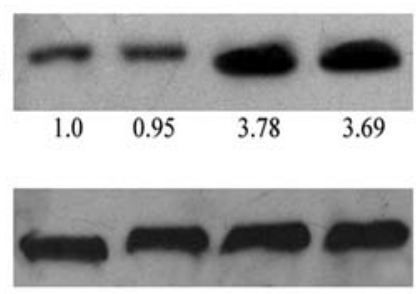

Anti-actin
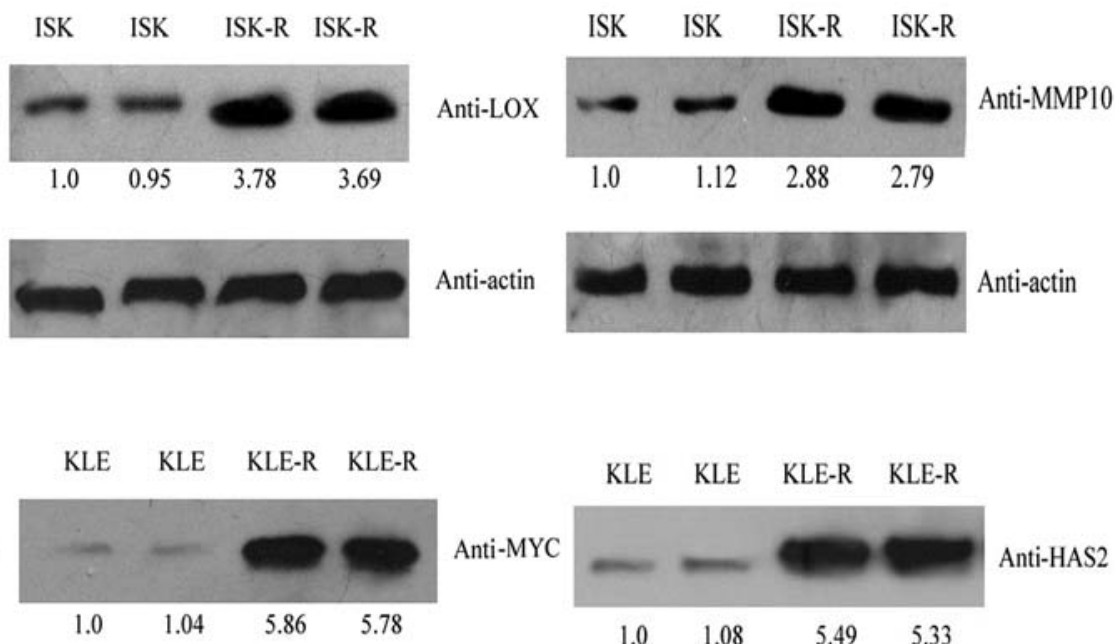

KLE KLE KLE-R KLE-R

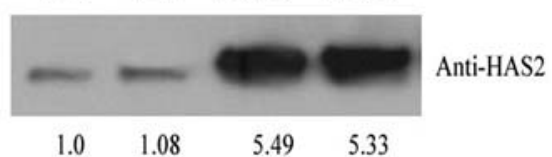

Anti-actin

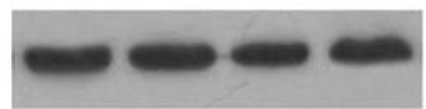


In radioresistant ISK cells, we found elevated expression of Heme oxygenase-1 (HMOX1, HO-1) after X-ray exposure. HMOX1 is believed to represent a key enzyme for the protection of cells against 'stress'. Elevated HMOX expression and activity was found in different types of human cancers such as human glioblastoma (14) and pancreatic cancer (15). HMOX1 was also found to accelerate cancer growth and contributes to cellular resistance against chemotherapy and radiotherapy $(15,16)$. Berberat and colleagues found that targeted knockdown of HMOX1 expression led to pronounced growth inhibition of the pancreatic cancer cells and made tumor cells significantly more sensitive to radiotherapy and chemotherapy. It is generally known that the destructive mechanisms of radiotherapy on cancer cells are mainly based on the generation of oxidative stress and the occurrance of radioresistance is a general clinical problem in cancer treatment. As a stress response gene, pronounced up-regulation of HMOX1 after first time treatment can lead to the resistance of further therapy. Therefore, specific inhibition of HMOX1 expression may be used as sensitizer to radiotherapy. No data on the expression of this gene in endometrial cancer have been reported until now and the molecular basis of these effects on cancers is not yet clear.

Another important factor in destructive mechanism of radiotherapy on cancer cells is the induction of apoptosis. We observed significant elevation in the percentage of apoptosis cells in KLE cells than ISK cells in response to irradiation. This may suggest that radiation is more effective in inducing early apoptosis in KLE cells. Among differently expressed genes related to apoptosis, $\mathrm{Mdm} 2 \mathrm{p} 53$ binding protein homolog (MDM2), Heat shock $70 \mathrm{kDa}$ protein 5 (HSPA5), Heat shock $70 \mathrm{kDa}$ protein 1A (HSP70-1A), Cysteine-rich 61 (CYR61), and Apolipoprotein E (APOE), which inhibit apoptosis, showed higher expression in ISK cells.

MDM2 is a target gene of the transcription factor tumor protein $\mathrm{p} 53$. Overexpression of this gene can result in excessive inactivation of tumor protein $\mathrm{p} 53$, diminishing its tumor suppressor function. This protein has E3 ubiquitin ligase activity, which targets tumor protein p53 for proteasomal degradation. Studies indicate that MDM2 has a critical role in regulating p53 response to DNA-damaging therapies (17). Inhibition of MDM2 has been shown to sensitize thyroid and lung cancer to ionizing radiation $(18,19)$. Cao and colleagues suggested that MDM2 inhibition sensitized the H460 lung cancer model to irradiation via induction of apoptosis and senescence as well as by enhancing the antivascular effects of radiation (19). However, the signals that regulate its expression and its role in radiosensitivity of endometrial cancer remain unknown.

HSPA5 and HSP70-1A are members of the heat-shock protein-70 (HSP70) family. They are involved in the folding and assembly of proteins in the endoplasmic reticulum and may play a key role in monitoring protein transport through the cell. Heat-shock proteins (Hsps) synthesis can be increased by cellular damage induced by radiation. Inducible Hsp70 has been suggested to have multiple roles in cytoprotection against apoptosis. Accordingly, high levels of Hsp70 prevent stress-induced apoptosis. Brondani and colleagues reported that the content of Hsp70 is associated with glioblastoma cell radioresistance (20). The overexpression of Hsp70 or/ and Hsp27 also enhanced radioresistance of mouse embryo fibroblasts (21). In the present study, we found that HSPA5 and HSP70-1A contents increased by 2.8 -fold and 2.2-fold in the ISK cells after radiation, respectively, but did not significantly change in the KLE cells. Thus, our results suggest that Hsp70 protection against radiation-induced apoptosis might underlie radioresistance of endometrial cancer, and further investigation should be conduct in the future.

The cell cycle of tumor cells often changes after irradiation. Tumor cells are known to be most sensitive to radiation-induced cell death when synchronized in the $G_{2} / M$ phase of the cell cycle, as the DNA is more vulnerable to radiation-induced damage during mitosis. We observed that more KLE cells arrested in $\mathrm{G}_{2} / \mathrm{M}$-phase than ISK cells in response to irradiation. This may partly explain why KLE cells are more radiosensitive than ISK in cell cycle kinetics. GADD45B (growth arrest and DNA-damage-inducible, beta) is a key member of nuclear proteins inducible by DNAdamaging stresses and play an active role in cell cycle adjustment that affects cell survival (22). GADD45 proteins interact with the complex of Cdk1 and CyclinB1, both of which are required for IR-induced cell cycle regulation and radioresistance (23). It has been long observed that IRinduced GADD45B expression is linked to p53 pathways. Recently, Wang and colleagues demonstrated that NK- $\kappa \mathrm{B}$, ERK and GADD $45 \beta$ are co-activated by ionizing radiation (IR) and coordinate in a loop-like signaling network to defend cells against the cytotoxicity induced by ionizing radiation and increase cell survival (24). Data from our study show that GADD45B was elevated in ISK cells after IR exposure. These findings suggest that GADD45B inhibition may also be used as a new option in endometrial cancer treatment.

In summary, the gene expression profiles derived in the current study define unique alterations in gene expression of endometrial cancer cells with different radiosensitivities. Our finding should be useful not only as an aid to find predicting radiosensitivity-related genes in endometrial cancer, but also as a means to find potential targets to sensitize radioresistant tumor cells and improve radiocurability. In future studies, the novel genes identified have to be evaluated in cancer models both in vitro and in vivo.

\section{Acknowledgements}

This work was supported by the grants from The Shandong Provincial Natural Science Foundation (No. Y2006C88).

\section{References}

1. Shaeffer DT and Randall ME: Adjuvant radiotherapy in endometrial carcinoma. Oncologist 10: 623-631, 2005.

2. Johnson N and Cornes P: Survival and recurrent disease after postoperative radiotherapy for early endometrial cancer: systematic review and meta-analysis. BJOG 114: 1313-1320, 2007.

3. Rantanen V, Grénman S, Kulmala J, Salmi T and Grénman R: Radiation sensitivity of endometrial carcinoma in vitro. Gynecol Oncol 44: 217-222, 1992.

4. Ogawa R, Ishiguro H, Kuwabara Y, et al: Identification of candidate genes involved in the radiosensitivity of esophageal cancer cells by microarray analysis. Dis Esophagus 21: 288-297, 2008. 
5. Watanabe T, Komuro Y, Kiyomatsu T, et al: Prediction of sensitivity of rectal cancer cells in response to preoperative radiotherapy by DNA microarray analysis of gene expression profiles. Cancer Res 66: 3370-3374, 2006.

6. Ojima E, Inoue Y, Miki C, Mori M and Kusunoki M: Effectiveness of gene expression profiling for response prediction of rectal cancer to preoperative radiotherapy. J Gastroenterol 42: 730-736, 2007.

7. Wong YF, Sahota DS, Cheung TH, et al: Gene expression pattern associated with radiotherapy sensitivity in cervical cancer. Cancer J 12: 189-193, 2006.

8. Guo Y, Guo H, Zhang L, et al: Genomic analysis of antihepatitis B virus (HBV) activity by small interfering RNA and lamivudine in stable HBV-producing cells. J Virol 79: 1439214403, 2005.

9. Chang JT, Chan SH, Lin CY, et al: Differentially expressed genes in radioresistant nasopharyngeal cancer cells: gp96 and GDF15. Mol Cancer Ther 6: 2271-2279, 2007.

10. Aravindan N, Madhusoodhanan R, Natarajan M and Herman TS: Alteration of apoptotic signaling molecules as a function of time after radiation in human neuroblastoma cells. Mol Cell Biochem 310: 167-179, 2008.

11. Guo WF, Lin RX, Huang J, Zhou Z, Yang J, Guo GZ and Wang SQ: Identification of differentially expressed genes contributing to radioresistance in lung cancer cells using microarray analysis. Radiat Res 164: 27-35, 2005.

12. Chinnaiyan P, Huang S, Vallabhaneni G, et al: Mechanisms of enhanced radiation response following epidermal growth factor receptor signaling inhibition by erlotinib (Tarceva). Cancer Res 65: 3328-3335, 2005.

13. Kitahara O, Katagiri T, Tsunoda T, Harima $Y$ and Nakamura $Y$ : Classification of sensitivity or resistance of cervical cancers to ionizing radiation according to expression profiles of 62 genes selected by cDNA microarray analysis. Neoplasia 4: 295-303, 2002.
14. Deininger MH, Meyermann R, Trautmann K, Duffner F, Grote EH, Wickboldt J and Schluesener HJ: Heme oxygenase (HO)-1 expressing macrophages/microglial cells accumulate during oligodendroglioma progression. Brain Res 882: 1-8, 2000.

15. Berberat PO, Dambrauskas Z, Gulbinas A, et al: Inhibition of heme oxygenase-1 increases responsiveness of pancreatic cancer cells to anticancer treatment. Clin Cancer Res 11: 3790-3798, 2005.

16. Sunamura M, Duda DG, Ghattas MH, et al: Heme oxygenase-1 accelerates tumor angiogenesis of human pancreatic cancer. Angiogenesis 6: 15-24, 2003.

17. Woods DB and Vousden KH: Regulation of p53 function. Exp Cell Res 1: 56-66, 2001.

18. Dilla T, Romero J, Sanstisteban P and Velasco JA: The mdm2 proto-oncogene sensitizes human medullary thyroid carcinoma cells to ionizing radiation. Oncogene 15: 2376-2386, 2002.

19. Cao C, Shinohara ET, Niermann KJ, Donnelly EF, Chen X, Hallahan DE and Lu B: Murine double minute 2 as a therapeutic target for radiation sensitization of lung cancer. Mol Cancer Ther 4: 1137-1145, 2005.

20. Brondani Da Rocha A, Regner A, Grivicich I, et al: Radioresistance is associated to increased Hsp70 content in human glioblastoma cell lines. Int J Oncol 25: 777-785, 2004.

21. Kabakov AE, Malyutina YV and Latchman DS: Hsf1-mediated stress response can transiently enhance cellular radioresistance. Radiat Res 165: 410-423, 2006.

22. Lu B, Ferrandino AF and Flavell RA: Gadd45beta is important for perpetuating cognate and inflammatory signals in T cells. Nat Immunol 5: 38-44, 2004.

23. Hassan KA, Ang KK, El-Naggar AK, et al: Cyclin B1 Overexpression and resistance to radiotherapy in head and neck squamous cell carcinoma. Cancer Res 62: 6414-6417, 2002.

24. Wang T, Hu YC, Dong S, et al: Co-activation of ERK, NFkappaB, and GADD45beta in response to ionizing radiation. J Biol Chem 280: 12593-12601, 2005. 